\title{
Parents, Peers, and Campus Involvement in the Transition to College
}

\author{
Jacquelyn M. Norris and Nina S. Mounts
}

The purpose of this research was to examine factors that contribute to a successful transition into college. It acknowledges the importance of parents, peers, and campus involvement during this developmental period. Ninety-six college freshmen were given a series of questionnaires that assessed parental support, friendship quality and friendship satisfaction, and campus involvement. The following outcome variables were examined: loneliness, sense of belongingness, and drug/alcohol use. The results suggest that higher quality friendships and higher satisfaction with friendships were significantly related to lower levels of loneliness. In addition, higher involvement in campus activities was significantly related to lower levels of loneliness. The results also show that higher levels of campus involvement were significantly related to higher levels of school belongingness, alcohol use, and binge drinking. Findings from this study suggest that there are multiple contexts related to adjustment during the transition to college.

Every year millions of American teenagers embark on a new path to college. This transition period, away from the familiar, is an important time in adolescence. Because of its relation to college success, it is, therefore, valuable to investigate this period. This investigation simultaneously examined the way in which parenting, peer relationships, and involvement in campus activities are related to adolescents' adjustment during the college transition. The outcomes explored through this research were: loneliness, school belongingness (an overall sense of belonging to the university), and alcohol/drug use. By exploring these areas, the researchers hope to provide a better understanding of the transition period.

\section{Parenting and the Transition to College}

Despite advances in technology that make it easier for parents and adolescents to stay connected during the transition to college, relationships with parents are an important predictor of success during the college transition. Much of the research on parenting and the college transition has focused on attachment, suggesting that perceived attachment with parents influences the success of a good college transition (Heiss, Berman, \& Sperling, 1996). Larose and Boivin (1998) found

Jacquelyn Norris (jacque.norris@gmail.com) is a first-year master's student in the Department of Adult \& Higher Education at Northern Illinois University.

Nina S. Mounts (nmounts@niu.edu) is an Associate Professor of Psychology at Northern Illinois University. 
that the amount of security that students felt towards parents during the transition was the most stable factor in predicting expectations about the transition in comparison to social support and emotional adjustment. The stability of the perceived security did not change during the transition; it remained constant for adolescents in their study.

Parenting style is another aspect of parenting that is important in making a positive adjustment to college. Wintre and Yaffe (2000) suggested that the authoritative parenting style is the most effective style of parenting to use during the transition to college. The authoritative parenting style is characterized by high levels of parental warmth and high levels of behavioral control (Lamborn, Mounts, Steinberg, \& Dornbusch, 1991). The authoritarian (low warmth, high behavioral control), permissive (high warmth, low behavioral control), and uninvolved (low warmth, low behavioral control) styles of parenting are less effective in supporting adolescent development during the college transition. In correlational analyses, authoritative parenting was related to students having lower levels of stress, lower levels of depression, and lower levels of loneliness. In addition, the authoritative style was related to higher levels of self-esteem and overall adjustment to the university.

Although the above mentioned investigations (Heiss, et al., 1996; Lamborn, et al., 1991; Larose \& Boivin, 1998; Wintre \& Yaffe, 2000) supported the notion that attachment and parenting style are important during the transition to college, Darling and Steinberg (1993) speculated that these aspects of parenting are difficult to change. Instead, parenting practices such as support might be easier to change. Thus, in this investigation the focus was on parental support during the college transition. The hope was that this investigation might be used to examine specific parenting practices that are effective in supporting the transition to college that could be introduced to parents by university orientation staff.

Several investigations have examined the relation between parental support and the adjustment to the first year of college. Mounts (2004) suggested that parents support the child financially, academically, and socially. In an ethnically diverse sample of college students, adolescents whose parents aided their transition through these three types of support were more likely to have a sense of belonging to the university and were more likely to have lower levels of depression and loneliness. In another study of undergraduates, parental support was an important factor in predicting adolescent's loneliness during the college transition (Mounts, Valentiner, Anderson, \& Boswell, 2006). Mounts and colleagues also found that when students in the study were low in parental support, low in sociability, and high in shyness, they were more likely to experience loneliness in college. Parental support also was related to friendship quality such that higher levels of parental support were found to be linked to higher levels of friendship quality during the transition to college (Mounts et al., 2006). In their short-term, longitudinal study of 144 freshman students, Dennis, Phinney, and Chuateco (2005) found that students who indicated that they were in need of support had lower college GPAs, poorer adjustment, and a lower commitment to college than those who indicated that they had family support 
readily available to them.

Although, to our knowledge, no investigations exist that examine the role of technology in facilitating parenting during the college transition, it is likely that technology does not contribute to the quality of parenting per se. Rather, the technological devices that the current generation of college students has at their disposal are simply another means of carrying out the parenting that is experienced in face-to-face interactions. That is, if in face-to-face interactions a relationship could be characterized as positive, it is likely that the positivity will be communicated through the many means available (e.g., text messages, e-mail, social networking sites). Similarly, if the relationship is generally high in negativity, that attitude is likely to be communicated through technology. In short, parents and adolescents are likely to use the various means of technology to communicate, not change the characteristics of the parent-child relationship.

\section{Peer Relationships and the Transition to College}

Although parents play an important role in students' transition to college, there are other factors, such as peer relationships, that are important. In addition to considering the role of parental support, the interactions and associations that college freshmen have with their peers during the transition to college are also examined in this investigation. Dennis et al. (2005) reported that peer support was statistically significantly related to adolescents' adjustment in college. The contribution of parental support to the college transition, while statistically significant, was smaller than that of the peers. Dennis and colleagues (2005) suggested that peers were able to provide the support and resources needed to succeed in school, whereas family members could not provide this specific kind of support. That is, students relied on peers to help them with problems at school, specifically academic problems (Dennis et al., 2005). By examining the relationships between peers, researchers can better understand the context in which the transition is happening.

In the transition to college, adolescents go through a major upheaval in their social network. Students must cope with leaving their close network of friends as well as try to make new friends. In a longitudinal study, Paul and Brier (2001) defined a concept called "friendsickness" to identify the loss or grief that is experienced during the transition. Even though it is seen as normal to experience friendsickness, students who were increasingly worried about losing pre-college friends experienced a more difficult adjustment to college. Friendsickness was correlated with loneliness and self-esteem such that higher levels of self-esteem were related to lower levels of loneliness. The outcome of poor self-esteem was related to a perceived decrease in competence as a friend. The ability to have a positive adjustment to college life decreased as loneliness increased when adolescents suffered from friendsickness. The impact that peers have on the transition should not be overlooked because they play an essential role in psycho social factors like loneliness. 


\section{Campus Involvement and the Transition to College}

A final factor that is likely to have a significant relationship with adolescents' adjustment to college is involvement in campus activities. In contrast to other investigations that focus on only one context that might contribute to adjustment, the current investigation examines the simultaneous contribution of parenting, peers, and campus involvement contexts to adolescents' adjustment. Early investigations by Astin $(1973,1975,1999)$ suggest that involvement in campus is related to retention in college. In one longitudinal study of college students, Astin (1975) suggested that numerous indicators of student involvement in the campus, such as involvement in extracurricular activities or part-time work on campus, were related to retention in college. More recently, researchers continue to examine student engagement in the campus and its relationship to a variety of student outcomes related to higher education (cf. Kuh, 2009 for review). Finally, involvement in campus activities might help students who have a history of poor social interactions obtain high quality friendships and experience less loneliness and social dissatisfaction (Bohnert, Aikins, \& Edidin, 2007).

\section{Aspects of College Adjustment}

There are a number of different outcomes that are of interest in relation to the transition to college. Much of the existing literature focuses on retention and grade point average as they are related to the transition to college. There are, however, other aspects of college adjustment that might be important in fully understanding the challenges associated with making the transition to college. Three aspects of college adjustment (loneliness, school belongingness, and alcohol/drug use) will be examined in the current investigation. The rationale for including each of these variables is presented below along with existing literature on the outcome variables.

\section{Loneliness}

Much of the college transition research includes aspects of loneliness as a measure of college adjustment; therefore, the current study also includes loneliness in order to examine the relationship it has with parental support, peer relationships, and campus involvement. As discussed earlier, studies have found that lower levels of loneliness in college students are reported when students have support from their parents (Mounts, 2004; Larose \& Boivin, 1998; Mounts et al., 2006). The studies that discussed peer relationships also had a loneliness component. Those who experienced friendsickness were more likely to be lonely, have a poor self-esteem, and be less confident regarding social acceptance (Paul \& Brier, 2001). In another study, the research displayed how the intensity of involvement also was influential in predicting loneliness and social dissatisfaction in adolescents who had poor-quality friendships before college (Bohnert, Aikins, \& Edidin, 2007). 


\section{School Belonging}

Along with loneliness, school belongingness is another outcome variable that is important to consider during the transition to college. This does not just include belonging within a peer group but to the larger group consisting of the university. The students who experience school belongingness see themselves as members of the university, not just as students who take classes on a college campus. A study by Pittman and Richmond (2007) revealed that when students felt like they were a part of the university, they did better in school in multiple aspects: the students had better grades, they experienced higher self-worth, and they underwent a relatively lower amount of externalizing problems. Pittman and Richmond (2007) also found that friendship quality was related to university belonging; however, they suggested that belongingness was a part of a larger construct that represented the overall university experience and community, not just interpersonal relationships.

Another study by Pittman and Richmond (2008) found the importance of the feeling students get when they have the sense of belonging at the university. The study related friendship quality to school belongingness. This longitudinal study also suggested that that a positive sense of school belongingness was related to lower levels of internalizing behavior problems. Pittman and Richmond also made a discrete distinction between friendship quality and university belongingness. Because it was longitudinal study, they were able to examine the changes over the two semesters and predict adjustment in friendship quality and university belongingness. Both of these factors are explored in the current research as well as the actual behaviors through the use of the involvement survey. The next section explores the use of alcohol and drugs on campus and how it affects the transition to college.

\section{Alcohol and Drug Use}

Male residential students tend to drink more alcohol than nontraditional commuter students who reside with their parents (Sessa, 2005). In addition, Sessa (2005) reported that commuting students tend to smoke more marijuana than non-commuting students. The substance of choice changes depending on where the adolescent resides. This indicates that the use of alcohol could be either associated with the separation from parents or the need to belong within a new community.

During the adjustment to college life, students may choose to use drugs and alcohol as a way of entering social contexts. Studies show that participation in "drinking games" (activities occurring in a social setting that regulate the amount of alcohol consumption) increases the likelihood that the adolescent will engage in binge drinking (Simons et al., 2005). The study found that males are more likely to consume higher amounts of alcohol, more often. Females are more likely to use over-the-counter and prescription medications. The research also found that the students who play drinking games are more likely to use nicotine and other drugs 
(Simons et al., 2005). These findings are important because they show the social aspect of alcohol and drug use.

Simons and colleagues (2005) also examined the influence of participation in collegiate sports and Greek organizations. They found that when students belonged to these groups they were more likely to engage in alcohol and drug use. These researchers attributed this behavior to the pressures associated with following the social norms of the group. Another study that looked specifically at alcohol use by collegiate athletes supported previous research in that it found that alcohol use is higher among athletes than the non-athlete population (Ford, 2007). The amount of perceived drinking by peers and the respondent's level of binge drinking were significantly related. This suggests, again, that social norms among the athletes contribute to binge drinking. Because alcohol consumption is seen as a normative behavior in this tight-knit group of athletes, individuals might feel that they must conform to the group expectations or else be ostracized by the team, which is the main social support for student athletes. Because these studies have shown the significance of alcohol/drug use in college student behaviors, it is of interest for the current study to explore how it related to the parenting, peer, and involvement variables.

\section{Current Investigation}

The purpose of this study was to investigate the relationship of parental support, peer relationships, and involvement on campus with loneliness, school belongingness, and alcohol/drug use during the transition to college. The hypotheses of this study were:

1. Higher amounts of parental support (financial, social, and academic) would be associated with lower levels of loneliness, higher levels of school belonging, and lower levels of alcohol/drug use.

2. Higher levels of friendship quality and friendship satisfaction would be associated with lower levels of loneliness, higher levels of school belonging, and higher levels of alcohol/drug use.

3. Higher amounts of campus involvement would be associated with lower levels of loneliness, higher levels of school belonging, and higher levels of alcohol/drug use.

\section{Method}

\section{Participants}

There were a total of 96 participants in this study, all in their first semester of college. The participants were introductory psychology students between the ages of 18 and 19 from a large Midwestern university. Thirty-one percent of the participants were male, and 69 percent were female. Prior to starting college, 61 percent of participants lived with both biological parents in the same home, 25 percent lived with a single parent (mother or father), 10 percent lived with a 
step-parent and parent, one percent lived with other relatives or guardians, and three percent lived on their own. As for marital status, 99 percent of participants were single, and one percent were married. Seventy-five percent of participants were 18 years old, and 25 percent were 19 years old. Twelve percent of participants identified themselves as African American, African, or Black. Six percent of participants were Asian or Asian American. Fifteen percent were Latino or Hispanic. One percent of participants were Middle Eastern. Sixty-six percent identified themselves as White, Caucasian, or European. One percent of participants were multi-racial. The gender composition of the sample was different than that of the wider institution in that $49 \%$ were male and $51 \%$ were female. The ethnic composition of the sample was similar to the ethnic composition of the wider institution.

\section{Measures}

Parental support for the college transition. In order to have a better understanding of the support levels each participant received from their parents, the Parental Support for the College Transition measure was used (Mounts, 2004). A total of 40 items asked participants about the amount of financial support, academic support, and social support they received from their parents during the transition to college. For each statement, the participants chose from a 4-point Likert scale ranging from 1 (strongly disagree) to 4 (strongly agree) to allow for interpretation of results, particularly means. A sample item from this scale was, "My parents/guardian paid tuition, room, and board for me to go to school." The internal consistency, or the assessment of how well the items work together, was assessed using Cronbach's alpha for several of the measures. Cronbach's alpha greater than .70 indicates good internal consistency of the items. The Cronbach's alpha for this scale was .88, indicating good internal consistency. The respondents' mean scores were used in the analyses.

McGill friendship satisfaction questionnaire. This scale examined satisfaction with a new college friendship (Mendelson \& Aboud, 1999). Participants were asked to "think of a close friend you have made since coming to campus" and express their feelings about this friendship on a continuum of agreement. The 9-point Likert scale ranged from: -4 (very much disagree); $-3 ;-2$ (somewhat disagree); -1, 0, 1, 2 (somewhat agree); and 3, 4 (very much agree). There were 16 items, and a sample item on this scale was, "I am happy with my friendship with ." Cronbach's alpha for this scale was .98, indicating high internal consistency. The respondents' mean scores were used in the analyses.

McGill friendship functions questionnaire. The McGill Friendship Questionnaire measured friendship quality by examining the functions of the new friendship. It closely examined whether the relationship fulfilled the six functions of a friendship including stimulating companionship, help, intimacy, reliable alliance, self-validation, and emotional security (Mendelson \& Aboud, 1999). Participants were again asked to "think of a close friend you have made since coming to campus" and then indicate how often each item applied to that friendship. The 
9-point Likert scale ranged from: 0 (never); 1, 2 (rarely); 3, 4 (once in a while); 5, 6 (fairly often) ; and 7, 8 (always). There were a total of 30 items, and a sample item on this scale was, "___ would make me feel comfortable in a new situation." Cronbach's alpha for this scale was .98, indicating high internal consistency. The respondents' mean scores were used in the analyses.

Campus involvement questionnaire. A total of nine items were created by the research team for this investigation. The first four items asked whether the adolescents had stayed on campus or returned home to spend time with family or friends over the four weekends prior to participation in the study. The weekends were listed separately as: Last Weekend, Two Weekends Ago, Three Weekends Ago, and Four Weekends Ago. They circled "yes" if they returned home or "no" if they stayed on campus for the entire weekend. They were asked to circle "yes" even if the trip home was very brief. For the last five items, participants indicated the number of on-campus activities they had participated in since starting college. For each activity, they wrote the number of times they attended that kind of event. There were five categories of events listed: Sporting Events (football games, intramural games, club sports), Student Organizations (any kind of activity that was planned by a student led organization, such as meetings or service projects), Educational Events (e.g., speakers, conferences), Dorm Activities (e.g., floor meetings, hall council, volleyball tournaments), and Social Events (e.g., parties, dances, lunch dates, formal dinners). These categories were identified by examining materials that presented activity options to undergraduate students at the university (e.g., websites) and grouping the activities into broader categories based on the focus of the activities. The list of activities was intended to assess all areas of campus activities.

UCLA loneliness scale: Version 3. To assess the level of loneliness the participant was experiencing during the college transition, the most current UCLA Loneliness Scale was used (Russell, 1996). Participants responded to the items by indicating how often they experienced the feelings in the statement. The responses ranged from 1 (never), 2 (rarely), 3 (sometimes), to 4 (often). There were a total of 20 items on this scale, and a sample item was, "How often do you feel there is no one you can turn to?" Cronbach's alpha for this scale was .92, indicating good internal consistency. The respondents' mean scores were used in the analyses.

Sense of belonging to the university. (Pittman \& Richmond, 2007; Goodenow, 1993). This scale was originally adapted from the Psychological Sense of School Membership (PSSM). It measures the feelings participants have towards the college in regard to belonging. There were 18 items which were statements that the participants indicated their level of agreement. A sample item was: "I feel like a real part of this school." The response categories ranged from: 1 (not at all true), 2 (almost never true), 3 (sometimes true), 4 (almost always true), to 5 (always true). Cronbach's alpha for this scale was .91, indicating good internal consistency. The respondents' mean scores were used in the analyses.

Thirty-day drug/alcohol use survey. This survey was designed to assess both frequency and intensity of drug and alcohol use (Deacon \& Valentiner, 2000). Questions asked about the frequency of alcohol use and binge drinking, and 
whether the participants had used certain drugs. They were asked to indicate the frequency of drug and alcohol use since coming to college and within the last thirty days; for all participants, this period started at least a month after coming to college.

The question indicating the frequency of alcohol use was: "In the past 30 days, about how often have you used alcohol (beer, wine, hard liquor, wine coolers)?" The response choices were: a. "every day," b. "5-6 days per week," c. "3-4 days per week," d. "1-2 days per week," e. "less often than weekly," and f. "not at all." The item for intensity of binge drinking was: "In the past 30 days, about how often have you had five alcoholic drinks in one sitting (beer, wine, hard liquor, wine coolers)?" The response categories were: a. "Every day," b. "5-6 days per week," c. "3-4 days per week," d. "1-2 days per week," e. "less often than weekly," and f. "not at all." For questions on the frequency of drug use, participants circled "yes" or "no"; a sample item was: "In the past 30 days, have you used cannabis including marijuana, hashish ('hash'), THC, 'pot,' 'grass,' 'weed,' or 'reefer'?"

\section{Procedures}

Participants were recruited through an online system designed for the introductory course in psychology. They were able to choose a day and time that fit into their schedule. Each participant was given one extra credit point in the psychology course for taking part in the study. Each participant reported to a classroom in the psychology building. The room had a large conference table at which the participants were seated; there were between one and fifteen students per collection session. After the students were seated, a consent form was given out to the participants to read and keep for their records. In order to protect the participants' anonymity, a waiver was given for signed consent from the institutional review board. That is, given that a signed consent form would be the only item that would identify the participants in the investigation, the institutional review board agreed that a written, but unsigned, consent form would protect the anonymity of the participants better than a written, signed, consent form. Potential participants were told by the researcher that purpose of the study was to learn about the transition to college, and they were also informed of the voluntary nature of the study. The paper and pencil survey packets were then distributed. It took 15 to 30 minutes for the participants to complete the entire packet. Upon completion of the survey, the participants returned the survey to the researcher who gave them the debriefing form. There were no experimental or control groups in the study; every participant completed the same survey.

\section{Data Analyses}

The measures that were included in the data analyses were, for the most part, continuous measures. That means that the respondents did not fall into specific groups, but rather their responses were mean scores on scales. Given this feature 
of the data, hierarchical regression analysis is the appropriate statistical method to use since analysis of variance would only be appropriate for data that could be classified into discrete groups. Five hierarchical regression analyses were conducted in which the outcome variables (i.e., loneliness, school belonging, frequency of alcohol use in the last 30 days, frequency of binge drinking in the last 30 days, and count of the variety of drugs used in the last 30 days) were regressed on parental support, friendship quality, friendship satisfaction, and campus involvement (two scales). Because parenting and peer relationships might vary as a function of gender, all analyses also included gender as a control variable.

\section{Results}

Means and standard deviations of the major variable are presented in Table 1. The intercorrelations among the major variables are presented in Table 2. The results from the regression analyses are presented in Table 3.

It was hypothesized that greater parental support would be associated with lower levels of loneliness; higher levels of school belonging; and lower levels of alcohol use, binge drinking, and drug use. There were no significant relationships between parental support and school belonging, $B=.17, p<.10$, loneliness, $B=-.08, n s ;$ alcohol use, $B=-.04, n s ;$ binge drinking, $B=-.06, n s ;$ or drug use, $B=-.06, n s$.

The second hypothesis examined whether more peer support would be associated with lower levels of loneliness, higher levels of school belonging, higher levels of alcohol use, binge drinking, and drug use. As predicted, results suggested that friendship satisfaction was related to lower levels of loneliness, $B=.25, p>.05$. Similarly, higher levels of friendship quality were related to lower levels of loneliness, $B=-.37, p>.01$. There were no significant relations between friendship satisfaction and school belonging, $B=.17$, $n s$; alcohol use, $B=.11$, $n s$; binge drinking, $B=.11$, ns; or drug use, $B=.16$, ns. There was also no significant association between friendship quality and school belonging, $B=.25, p>.10$, alcohol use, $B=.07$, ns; binge drinking, $B=.02$, ns; or drug use, $B=-.12$, ns.

The last hypothesis predicted that greater campus involvement would be associated with lower levels of loneliness, higher levels of school belonging, and higher levels of alcohol use, binge drinking, and drug use. There was no evidence to suggest an association between the number of weekends students spend at school and the following variables: loneliness, $B=-.10, n s$; school belonging, $B=-.01$, ns; alcohol use, $B=-.07$, ns; binge drinking, $B=-.16, n s$; and drug use, $B=-.01$, ns. However, the data did suggest that the number of activities did have a negative impact on loneliness such that higher levels of campus involvement were related to lower amounts of loneliness, $B=-.25, p>.01$, and that higher amounts of campus involvement were related to higher levels of school belonging, $B=-.29$, $p>.01$. The evidence also suggested that higher levels of campus involvement were related to higher levels of alcohol use, $B=.23, p>.05$ as well as higher amounts of binge drinking, $B=.22, p>.05$. There was not a significant relationship between campus involvement and drug use, $B=-.02$, ns. 


\section{Discussion}

The purpose of the current investigation was to examine the relationships between parental support, friendship quality, friendship satisfaction, and campus involvement and adolescents' adjustment to college. By examining several factors that might contribute to a better overall adjustment, this research hopes to provide a understanding of what factors contribute to more successful period of transition and what it means for the field of college administration and student development.

The first hypothesis concerning parental support was not fully supported by the results, which contradicts the findings of previous research (Mounts, 2004; Mounts et al., 2006). There were three relationships examined in association to parental support. The current investigation did not find a relationships between parental support and loneliness, which was contrary to the results of Mounts and colleagues (Mounts, 2004; Mounts et al., 2006). Both studies by Mounts and colleagues suggested that higher levels of parental support were related to lower levels of loneliness during the transition to college. The current study suggests that parental support is not related to the level of loneliness that students experience. However, a close inspection of the zero order correlations for the current investigation in comparison with the Mounts (2004) investigation suggests that the correlations are of similar magnitude (approximately $r=-.17$ ). However, the Mounts (2004) investigation had a larger sample size, which contributed to the correlation being statistically significant, although the pattern of the correlation was similar across the two investigations. Thus, the smaller sample size of the current investigation might explain these seemingly discrepant findings.

Parental support was related to school belongingness. This was consistent with research by Mounts (2004) in that higher levels of parental support were related to a higher sense of belonging at the university. This suggests that the parent's role in helping the student adjust to college life is still important. One of the previous research investigations on school belongingness did not look at parental support (Pittman \& Richmond, 2007).

Contrary to the hypotheses, parental support was not significantly related with alcohol, binge drinking, or drugs. The current study was not consistent with the results found by Sessa (2005), which reported that separation from parents was associated with higher alcohol use. The current study did not compare on-campus residents and commuter students as did Sessa's investigation, so drug use in the commuter students would clearly not have shown in these results. However, the lack of a relationship between on-campus students and drug use did again appear. Since there was only a repetition of non-significant results, it would be interesting to explore these variables more in-depth for future studies.

The second hypothesis explored the relationships between peer relationships and the outcome variables of loneliness, school belongingness, alcohol use, binge drinking, and drug use. As hypothesized, the results suggested that positive relationships with peers contribute to lower levels of loneliness. Both the friendship satisfaction and friendship quality measures were significantly related to loneliness. This finding supports previous research which looked at this aspect 
of the transition (Dennis et al., 2005; Paul \& Brier, 2001).

This study is not consistent with previous studies in that the relationship between peers and university belongingness was not significant. Pittman and Richmond (2007) suggested that university belongingness was related to friendship quality. However, this was not the case in the current investigation. Although the same school belonging measure was used in both studies, this research did not investigate both university belonging and high school belonging.

The current research did not find a relationship between friendship quality and alcohol/drug use. This could indicate that the quality of a close dyadic relationship is less important in the peer influence process than other types of college peer relationships. It could be the norms of the larger peer group available on campus might be more important in determining alcohol and drug use than the quality of the relationship with friends. Along with conducting the investigation with a larger sample of adolescents, future investigations might assess the way in which the quality of dyadic relationships (i.e., friendships) contribute to alcohol and drug use versus the alcohol and drug use norms of the larger campus community. Thus, future investigations might examine different types of peer relationships during the college transition, such as close friendships or acquaintanceships, and the association of these different types of peer relationships to alcohol/drug use.

The third hypothesis focused on campus involvement in relation to loneliness, school belongingness, alcohol use, binge drinking, and drug use. Campus involvement was measured in two ways: weekends spent on campus and number of activities in which the student had been involved. There was no relationship between the number of weekends spent on campus and the outcome variables. This finding was surprising because generally it could be perceived that the more time students spent at home, the less likely they are to be active on campus (Astin, 1999). Future investigations might assess time spent at home in more detail.

The second method of measuring campus involvement assessed the number of activities students were involved in relation to the variables loneliness, school belongingness, alcohol use, and binge drinking. Involvement in campus activities was related to lower levels of loneliness in students. This result is consistent with previous research by Bohnert et al. (2007). In addition, there was a positive relationship between campus involvement and school belonging. This expands previous investigations that examined campus involvement (cf. Astin, 1999). Consistent with the work of Astin (1999) which suggested a positive relationship between involvement and college retention, the number of activities adolescents participated in was related to loneliness such that higher levels of campus involvement were related to lower amounts of loneliness (also consistent with Bohnert et al., (2007)). For students transitioning to college, anxiety about handling the new academic demands in the college environment and advice from parents might prevent adolescents from fully participating in college activities. Thus, orientation professionals might explicitly address the benefits that accrue through participation in college activities. Future investigations might examine the 
different types of activities in more detail (Astin, 1999). In addition, Astin (1999) suggests that involvement in college activities might be linked to peer relationships as the college levels. Although the current investigation documents that both participation in activities and friendship quality and satisfaction contribute to adjustment during the college transition, it does not examine the ways in which participation in activities might facilitate the development of friendships or, alternatively, the ways in which friendships might support involvement in activities. Thus, future investigations might detail the way in which involvement in activities are linked to friendships during the transition to college.

Consistent with the hypotheses, the evidence also suggested that higher levels of campus involvement were related to higher levels of alcohol use and binge drinking. Previous investigations have reported similar patterns of alcohol use (Simons et al., 2005) such that students who participated in collegiate sports and Greek organizations engaged in higher levels of alcohol and drug use. Similarly, Ford (2007) reported higher alcohol use among athletes than non-athletes. A limitation with the current investigation is that the data for the different campus activities were not analyzed separately by activity type. It is likely that if the data were analyzed separately a pattern of findings would emerge such that sports and Greek activities were related to higher levels of alcohol use. One of the ongoing challenges for colleges and universities to navigate is supporting student participation in sports and Greek activities while at the same time developing strategies for discouraging the excessive alcohol use that often accompanies these activities.

There was not a significant relationship between involvement in campus activities and adolescents' drug use during the transition to college. One possible reason for the lack of relationship could be because there is not a high level of drug use among college freshmen. Indeed, the mean for drug use was substantially lower than the mean for alcohol use and binge drinking. In addition, because of concerns about illegal activity it could be that participants did not want to admit to drug use. Even though they were reminded multiple times of the anonymity of the study, students still might not be comfortable revealing that information. Illegal alcohol consumption is more socially accepted and could be considered a stereotypical norm for college freshmen. Illegal drug use comes with a stigma, higher ramifications, and higher legal consequences. 
TABLE 1

\section{Means and standard deviations of the major variables}

Variables

Parental Support

Friendship Satisfaction

Friendship Quality

Campus Involvement -Weekends

Campus Involvement - Activities

Loneliness

Belongingness

Alcohol Use

Binge Drinking

Drug Use
Means

2.67

2.85

6.43

1.99

3.68

2.05

3.50

1.20

.78

.35
Standard Deviations

.41

1.41

1.44

1.14

2.89

.57

.69

.93

.85

.65 


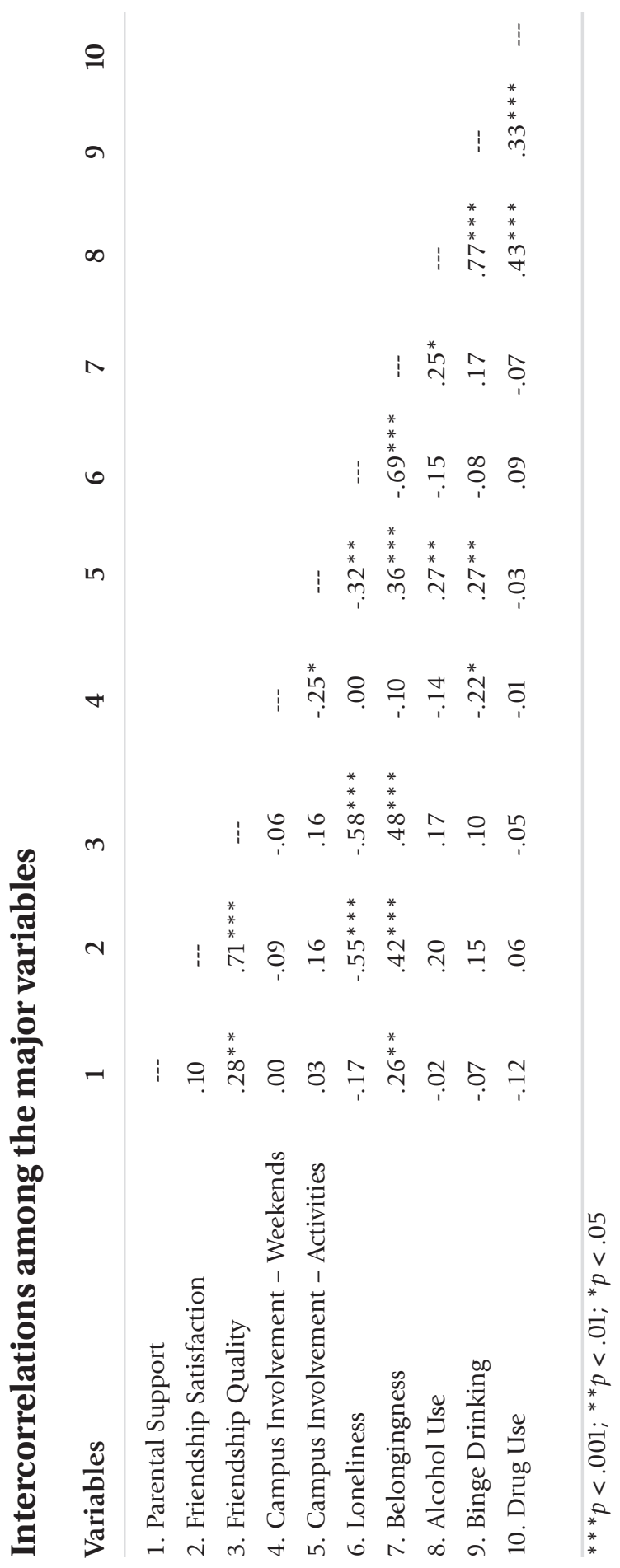




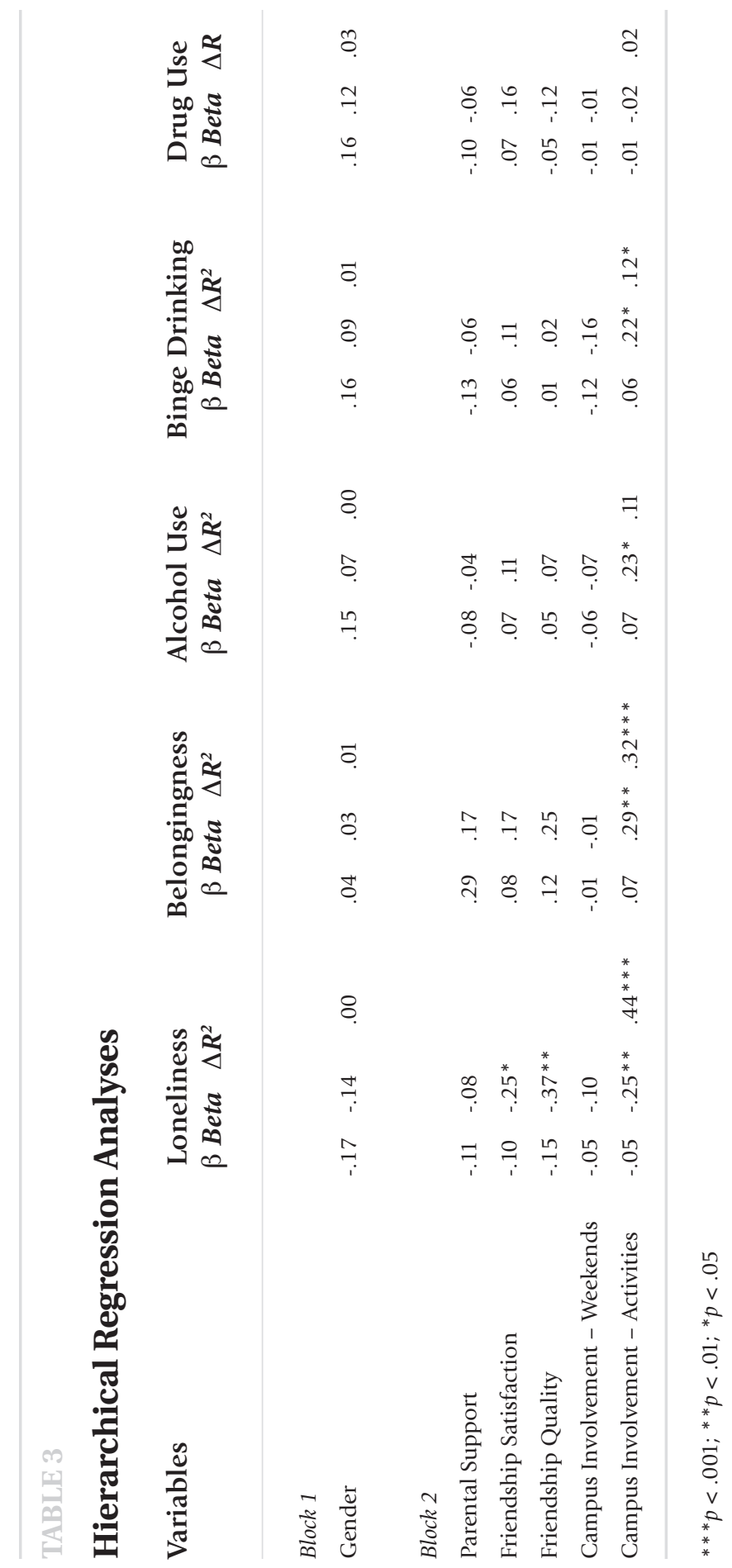


Astin, A. W. (1973). The impact of dormitory living on students. Educational Record, $54,204-210$.

Astin, A. W. (1975). Preventing students from dropping out. San Francisco: Jossey-Bass.

Astin, A. W. (1999). Student involvement: A developmental theory for higher education. Journal of College Student Development, 40, 518-529.

Bohnert, A. M., Aikins, J. W., \& Edidin, J. (2007). The role of organized activities in facilitating social adaptation across the transition to college. Journal of Adolescent Research, 22, 189-208.

Darling, N., \& Steinberg, L. (1993). Parenting style as context: An integrative model. Psychological Bulletin, 113, 487-496.

Deacon, B. J., \& Valentiner, D. P. (2000). Substance use and non-clinical panic attacks in a young adult sample. Journal of Substance Abuse, 11, 7-15.

Dennis, J. M., Phinney, J. S., Chuateco, L. I. (2005). The role of motivation, parental support, and peer support in the academic success of ethnic minority first-generation college students. Journal of College Students Development, 46(3), 223-236.

Ford, J. A. (2007). Alcohol use among college students: A comparison of athletes and nonathletes. Substance Use \& Misuse, 42, 1367-1377.

Heiss, G. E.; Berman, W. H.; \& Sperling, M. B. (1996). Five scales in search of a construct: Exploring continued attachment to parents in college students. Journal of Personality Assessment, 67(1), 102-115.

Goodenow, C. (1993). The psychological sense of school membership among adolescents: Scales development and educational correlates. Psychology in the Schools, 30, 79-90.

Kuh, G. D. (2009). What student affairs professionals need to know about student engagement. Journal of College Student Development, 50, 683-706.

Lamborn, S. D., Mounts, N. S., Steinberg, L., \& Dornbusch, S. M. (1991). Patterns of competence and adjustment among adolescents from authoritative, authoritarian, indulgent, and neglectful families. Child Development, 62, 1049-1065.

Larose, S., \& Boivin, M. (1998). Attachment to parents, social support expectations, and socioemotional adjustment during the high school-college transition. Journal of Research on Adolescence, 8, 1-27.

Mendelson, M. J., \& Aboud, F. (1999). Measuring friendship quality in late adolescents and young adults: McGill Friendship Questionnaires. Canadian Journal of Behavioral Sciences, 31, 130-132.

Mounts, N. S. (2004). Contributions of parenting and campus climate to freshmen adjustment in a multiethnic sample. Journal of Adolescent Research, 19, 468-491.

Mounts, N. S., Valentiner, D. P., Anderson, K. L., \& Boswell, M. K. (2006). Shyness, sociability, and parental support for the college transition: Relation to adolescents' adjustment. Journal of Youth and Adolescence, 35, 71-80.

Paul, E. L., \& Brier, S. (2001). Friendsickness in the transition to college: Precollege predictors and college adjustment correlates. Journal of Counseling and Development, 79, 77-89. 
Pittman, L. D., \& Richmond, A. (2007). Academic and psychological functioning in late adolescence: The importance of school belonging. Journal of Experimental Education, 75(4), 270-290.

Pittman, L. D. \& Richmond, A. (2008). University belonging, friendship quality, and psychological adjustment during the transition to college. Journal of Experimental Education, 76(4), 343-361.

Russell, D. W. (1996). UCLA loneliness scale (version 3); Reliability, validity, and factor structure. Journal of Personality Assessment, 66(1), 20-40.

Sessa, F. M. (2005). The influence of perceived parenting on substance use during the transition to college: A comparison of male residential and commuter students. Journal of College Student Development, 46(1), 62-74.

Simons, L., Klichine, S., Lantz, V., Ascolese, L., Deihl, S., Schatz, B., \& Wright, L. (2005). The relationship between social-contextual factors and alcohol and polydrug use among college freshmen. Journal of Psychoactive Drugs, 37, 415-424.

Wintre, M. G., \& Yaffe, M. (2000). First-year students' adjustment to university life as a function of relationships with parents. Journal of Adolescent Research, 15, 9-37. 